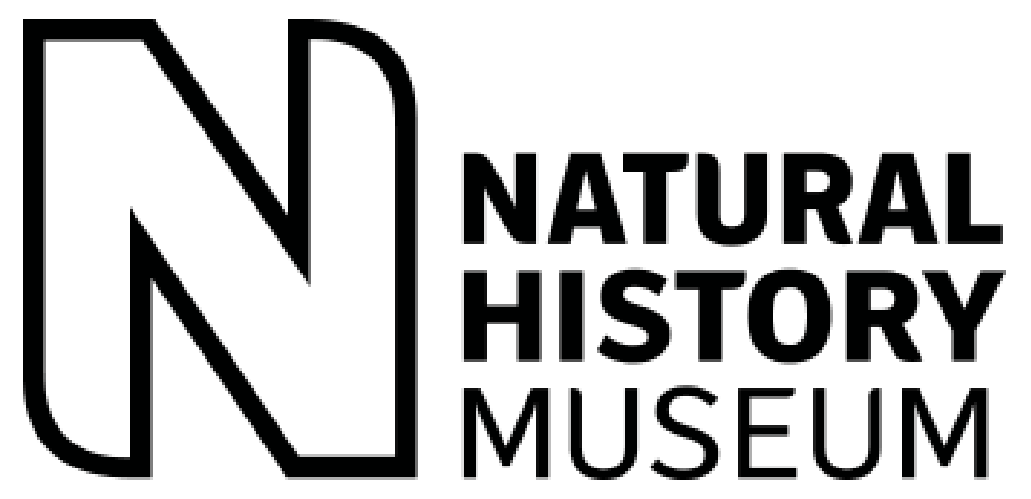

\begin{tabular}{|l|l|}
\hline Title & The Caribbean needs big marine protected areas \\
\hline Authors & $\begin{array}{l}\text { Gallagher, AJ; Amon, Diva; Bervoets, T; Shipley, ON; } \\
\text { Hammerschlag, N; Sims, DW }\end{array}$ \\
\hline Date Submitted & $2020-09-11$ \\
\hline
\end{tabular}




\section{The Caribbean needs big marine protected areas}

Large-scale marine protected areas (MPAs) $\left(>240,000 \mathrm{~km}^{2}\right)$ seek to protect and connect large pelagic ecosystems, enhance ecological processes, and promote socioeconomic benefits including sustainable fisheries (1). One of their greatest benefits is the potential to conserve highly migratory species such as sharks, which can travel long distances spanning multiple national exclusive economic zones (2). Despite a growing international interest among many national governments, nongovernmental organizations, and academic and philanthropic communities to create large-scale MPAs, the Greater Caribbean, which contains the greatest diversity of marine biota in the Atlantic Ocean (3), has been grossly overlooked.

There are currently 33 large-scale MPAs, but not one is in the Caribbean Sea. Although there is a rich history of the establishment of MPAs in the Greater Caribbean (4), the majority allow fishing (5) and do not take into account the full representation of ocean habitats and connectivity required to encompass the space use of migratory species. Large sharks are overfished in the region; because they are caught locally in high numbers, they are sparse across most of the Greater Caribbean (6). [The Mediterranean ocean basin, which is similarly lacking in largescale MPAs, provides another glimpse of this trend-there, large sharks there have virtually disappeared due to fishing pressure (8)]. Fortunately, in certain countries where commercial longline fishing has been banned (such as The Bahamas), shark populations remain strong, thereby contributing millions of dollars to local economies through dive ecotourism (7).

The Greater Caribbean region relies on healthy oceans to drive tourism and sustain livelihoods. These developing nations are poised to face mounting pressures for access to fisheries in return for development, as well as the increasing impacts of habitat degradation and climate change. MPA creation and enforcement is admittedly complex. However, to arrest the decline of threatened species in the region, establishing large-scale MPAs in the Greater Caribbean is both an opportunity and a necessity.

Austin J. Gallagher ${ }^{1 *}$, Diva J. Amon², Tadzio Bervoets ${ }^{3}$, Oliver N. Shipley ${ }^{4}$, Neil Hammerschlag ${ }^{5}$, David W. Sims ${ }^{6,7}$

${ }^{1}$ Beneath the Waves, Herndon, VA xxxxx, USA ${ }^{2}$ Department of Life Sciences, Natural History Museum, London, UK. ${ }^{3}$ Dutch Caribbean Nature Alliance, Kralendijk, Bonaire. ${ }^{4}$ School of Marine and Atmospheric Sciences, Stony Brook University, Stony Brook, NY xxxxx, USA. ${ }^{5}$ Rosenstiel School of Marine and Atmospheric Science, University of Miami, Miami, FL $x x x x x$, USA. ${ }^{6}$ Marine Biological Association of the UK Plymouth, PL1 2PB, UK. ${ }^{7}$ University of Southampton, Southampton, SO14 3ZH, UK.
*Corresponding author. Email: austin@beneaththewaves.org

REFERENCES AND NOTES

1.R. Toonen et al., Mar. Poll. Bull. 77, 7 (2013).

2.N. Queiroz, Nature 572, 461 (2019).

3.C. M. Roberts et al., Science 295, 1280 (2002).

4.G. Bustamante et al., Aquat. Conserv. Mar. Fresh. Ecosyst. 24, 153 (2014).

5.A. P. Guarderas, S. D. Hacker, J. Lubchenco, Conserv. Biol. 22, 1630 (2008).

6.C. A. Ward-Paige et al., PLOS One 8, e11968 (2010).

7.A. J. Gallagher, N. Hammerschlag, Curr. Issue. Tourism 14, 797 (2011).

8.F. Ferretti, R. A. Myers, F. Serena, H. K. Lotze, Conserv. Biol. 22, 952 (2008)

10.1126/science.abb0650 